\title{
Effects of Flue Spaces on the Initial In-Rack Plume Flow
}

\author{
HAUKUR INGASON \\ Swedish National Testing and Research Institute (SP) \\ Box 857, S-501 15 BORÅS, Sweden
}

\begin{abstract}
This paper describes the effects of the vertical flue space (gap) on the convective Heat Release Rate (HRR) and the in-rack plume flow in rack storage fires. Four large-scale tests with Standard Class II commodity, which consists of double triwall corrugated board cartons, were carried out with vertical flue spaces of $75 \mathrm{~mm}, 150 \mathrm{~mm}, 225 \mathrm{~mm}$ and $300 \mathrm{~mm}$. Measurements of convective HRR per height of the rack storage, in-rack flame height, centreline excess gas temperature, centreline gas velocity and in-rack temperature profiles are presented. The objective of the study was to compare the results of the four full-scale rack storage tests to the results of the 1:3 model-scale tests and one large-scale test carried out in an earlier study [1].
\end{abstract}

KEYWORDS: Heat Release Rate (HRR), in-rack plume flow, flame height, flue space

\section{NOTATION}

a empirical constant in eqn (2)

b empirical constant in eqn (2)

$\mathrm{c}_{\mathrm{p}} \quad$ specific heat $(\mathrm{kJ} / \mathrm{kg} \mathrm{K})$

$\mathrm{h} \quad$ height of the horizontal flue (mm)

$\mathrm{H}$ total height of the rack storage (m)

$L_{f} \quad$ in-rack flame length (m)

Q chemical HRR (kW)

$\mathrm{Q}_{\mathrm{c}} \quad$ convective HRR $(\mathrm{kW})$

$\mathrm{R}$ linear correlation coefficient

$\Delta T_{0} \quad$ excess centreline temperature (K)

$T_{\infty} \quad$ ambient temperature (K) $\mathrm{t} \quad$ time from ignition ( $\mathrm{s}$ )

$\mathrm{t}_{0} \quad$ incipient time of fire growth (s)

$\mathrm{u}$ centreline gas velocity $(\mathrm{m} / \mathrm{s})$

w vertical flue space $(\mathrm{mm})$

$\mathrm{x}$ horizontal distance from centreline of the rack storage (m)

$\mathrm{z} \quad$ elevation above floor $(\mathrm{m})$

$\mathrm{z}_{0} \quad$ virtual source height $(\mathrm{m})$

$\rho_{\infty} \quad$ ambient density $\left(\mathrm{kg} / \mathrm{m}^{3}\right)$

$\alpha \quad$ fire growth parameter $\left(\mathrm{kW} / \mathrm{s}^{3}\right)$

$\alpha_{e} \quad$ empirical constant in eqn (2) $(\mathrm{kW} / \mathrm{m})$

$\beta \quad$ empirical constant in eqn (2) $\left(\mathrm{s}^{-1}\right)$ 


\section{INTRODUCTION}

The need for better information and understanding of early fire growth of rack storage fires is of great importance, both for engineers and for the fire brigade. The present study focuses on the influence of the flue space (the vertical gap between the boxes stored in the rack) on the convective HRR and the in-rack flow conditions. Ingason [1] has previously presented simple in-rack fire plume correlations, which can be used to predict the flow conditions inside vertical flues of rack storage. The correlations presented were mainly based on one large-scale test using Standard Class II commodity (double triwall corrugated paper cartons). Additionally, data from 1:3 scale model tests with single-wall corrugated paper cartons folded inside with four single-wall corrugated board sheets were shown to correspond well to the single large-scale test. Ingason concluded that there is a great need for further large-scale testing in order to validate these correlations. The present study therefore includes four large-scale experiments with Standard Class II commodity in palletised rack storage, where HRRs (chemical and convective), in-rack gas temperatures, in-rack gas velocities and in-rack flame height were measured for different flue widths. The data and the correlations presented can provide an important base for future modelling work of flame spread in rack storage fires.

\section{THEORETICAL ASPECTS}

\section{Heat Release Rate (HRR)}

There are few studies available which have relevance to HRR in rack storage fires. $\mathrm{Yu}$ and Stavriandidis [2] found that the convective HRRs per tier correlates with a power-law dependence on time to the third power for rack storage fires. The fuel used in the study consisted of polystyrene cups packaged in compartmented, single- wall corrugated paper cartons. The convective HRR per tier is given according to the following equation:

$$
Q_{c}=\alpha\left(t-t_{0}\right)^{3}
$$

where $\alpha$ is a fire growth coefficient $\left(\mathrm{kW} / \mathrm{s}^{3}\right)$ per tier, $\mathrm{t}$ is the time in seconds and $\mathrm{t}_{0}$ is the incipient time of fire growth (s). A data fit yielded $\alpha=0.0448 \mathrm{~kW} / \mathrm{s}^{3}$ per tier. This function worked well for the initial fire growth rate period, i.e., convective HRRs up to $800 \mathrm{~kW}$ per tier, which corresponds to $3200 \mathrm{~kW}$ for the 4-tier large-scale test presented here. The fire growth rate coefficient $\alpha$ in Yu and Stavriandidis [2] correlation for 4-tier high rack storage is $0.179 \mathrm{~kW} / \mathrm{s}^{3}(4$ $\mathrm{x}$ 0.0448).

Ingason [3] presented another type of mathematical representation of the convective HRR for rack storage fires. Based on the results from an analysis of large-scale experimental data extracted from references [4,5,6], Ingason [3] found that the initial convective HRR could be represented by the following type of mathematical expression:

$$
Q_{c}=H \alpha_{e} e^{\beta t}(a+b t)
$$

where $\alpha_{e}$, a, b and $\beta$ are empirical constants which can be determined from experimental data. $\mathrm{H}$ is the total height of the storage. The experimental data used in the analysis are presented in Fig. 1. The fuel array was two-pallet loads wide, two-pallet loads deep and two, three, four and five tiers high. The vertical flue widths were $150 \mathrm{~mm}$ and the horizontal flue heights were $330 \mathrm{~mm}$ (top of goods to pallet), which means that the effects of the flue spaces on the HRR cannot be 
considered. However, a comparison with the results given in the present study is of interest due to the difference in the burning commodity. The ignition source in these tests was a standardized one, i.e. four separate ignition sources symmetrically placed at the centre flue space of the fuel array and at the bottom of each carton at the lowest tier, see Ingason [3]. The size of each ignition source was estimated to be about $10-20 \mathrm{~kW}$. For further information about the different materials, see Ingason [3]. Fig. 1 indicates three distinct groups of fire growth rates. A fast fire growth rate (Group 1) $\left(\alpha_{e}=1.41 \mathrm{~kW} / \mathrm{m}^{2}, \beta=0.036 \mathrm{~s}^{-1}, \mathrm{a}=0.4 \mathrm{~m}\right.$ and $\mathrm{b}=1.57 \mathrm{~m} / \mathrm{s} ; \mathrm{R}=0.99=$ linear correlation coefficient), an intermediate fire growth rate (Group 2) $\left(\alpha_{e}=0.65, \beta=0.015, \mathrm{a}=0.4\right.$ and $\mathrm{b}=4.5 ; \mathrm{R}=0.94)$, and a relatively slow fire growth rate (Group 3 ) ( $\alpha_{e}=0.36, \beta=0.024, \mathrm{a}=0.4$ and $\mathrm{b}=0.99 ; \mathrm{R}=0.93$ ). The negative value of a obtained by curve fit in reference [3] is not physically justified. Therefore, it was assumed that a is equal to $0.4 \mathrm{~m}$, which corresponds to the width of the initial pyrolysis zone created by four ignition sources.

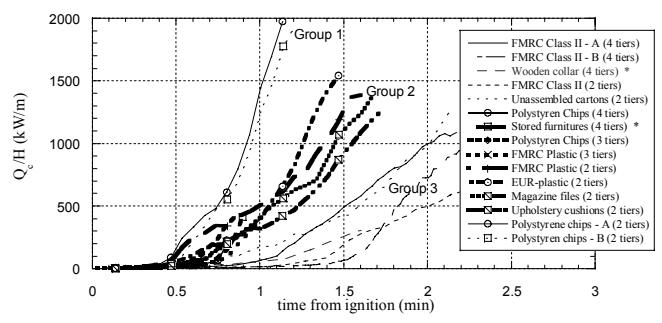

Fig. 1 - The convective HRR $\left(Q_{c}\right)$ per height of the rack $(H)$ as a function of time. The word 'tier' indicates the number of levels of the rack storage $(\approx 1.2$ - $1.5 \mathrm{~m} /$ tier; four pallets at each tier). Indices $A$ and $B$ indicate two different tests with similar conditions. FMRC Class II-A (4 tiers) is included in the new test series presented here, with $w=150 \mathrm{~mm}$, and FMRC Class II-B (4 tiers) is the large-scale test used in the earlier study by Ingason [1].

Equation (2) has not been validated for higher $\mathrm{Q}_{\mathrm{c}}$ than $7 \mathrm{MW}$ (or $\mathrm{Q}=10 \mathrm{MW}$ ), and therefore should be used with caution for $\mathrm{Q}_{\mathrm{c}}>7 \mathrm{MW}$. The fire does not necessarily develop in the same rapid way for higher HRRs and similar geometries. Group 1 includes polystyrene chips in paper cartons, Group 2 includes mainly plastic commodities in and without paper cartons, and Group 3 include natural materials such as cartons with thick walls and wood. In Group 3 we find the one of the Standard Class II tests performed in the present study (FMRC Class II-A (4 tiers), and the old large-scale test performed in an earlier study [1] (FMRC Class II-B (4 tier)). There appears to be a slight difference in the incipient time of the fire growth between these two tests. The reason for this difference is not known. No consideration was given to the incipient time, i.e. $t_{0}=0$, in the analysis of the curves shown in Fig. 1. In the work done by Ingason [3] it was found that $\mathrm{t}^{3}$ representation of the fire growth rate, without using $t_{0}$, yielded nearly as good results as Eqn. (2). Equation (1) is, however, not based on any physical model. Ingason [3] used a simple theory of upward and horizontal flame spread to obtain the mathematical representation given by Eqn. (2). In that model, the parameter a corresponds to the width of the initial pyrolysis zone, $b$ relates to the horizontal flame spread (on vertical surfaces), $\alpha_{e}$ relates to the HRR per square metre of burning material and the height of the initial pyrolysis zone and $\beta$ relates to the flame length, flame radiation and thermal properties of the burning material. The effect of the height, H, (see Eqn. (2)) on the convective HRR was not explained in the paper.

\section{In-rack plume correlations}


Recently, Ingason [1] presented axi-symmetric power law correlations for the in-rack flame height, $\mathrm{L}_{\mathrm{f}}$, the in-rack centreline excess gas temperatures, $\Delta T_{0}$, and the in-rack centreline velocity, $\mathrm{u}$. In the earlier study [1], the vertical flue widths, $\mathrm{w}$, in the model-scale tests were $\mathrm{w}=50 \mathrm{~mm}, 75 \mathrm{~mm}$ and $150 \mathrm{~mm}$, and in the large-scale test (only one test performed) the vertical flue width was $150 \mathrm{~mm}$. The horizontal flue height, $\mathrm{h}$, varied in the model-scale test for $\mathrm{w}=50 \mathrm{~mm}(\mathrm{~h}=50 \mathrm{~mm}$, $75 \mathrm{~mm}$ and $100 \mathrm{~mm}$ ), but was kept constant for $\mathrm{w}=75 \mathrm{~mm}$ and $\mathrm{w}=100 \mathrm{~mm}$ at $\mathrm{h}=50 \mathrm{~mm}$. In the large-scale test, which is nearly identical to one of the new tests presented here, the height of the horizontal flues was $\mathrm{h}=300 \mathrm{~mm}$. The effects of the horizontal flue heights were not explicitly considered in the derivation of these correlations. It was speculated that the effects, if any, might be hidden in the scatter of the experimental data. In the following, a summary of the in-rack plume correlations from [1] is given. A least square fit (model-scale tests and one large-scale test) to the in-rack flame height data yielded the following equation:

$$
L_{f}=-3.73 w+0.343 Q^{2 / 5}
$$

where $w$ is the vertical flue width in metre and Q is the total HRR in $\mathrm{kW}$. Equation (3) is valid for $L_{f}<H$, where $\mathrm{H}$ is the height of the rack storage. Ingason [1] also presented correlations for in-rack excess centreline temperature and velocity. The excess temperature is given by the following equation (based on one large-scale test):

$$
\Delta T_{0}=28\left[\frac{T_{\infty}}{g c_{p}{ }^{2} \rho_{\infty}{ }^{2}}\right\rceil^{1 / 3} \frac{Q_{c}{ }^{2 / 3}}{\left(z-z_{0}\right)^{5 / 3}}
$$

where $\mathrm{Q}_{\mathrm{c}}$ is the convective HRR in $\mathrm{kW}, \mathrm{cp}=1.01 \mathrm{~kJ} / \mathrm{kg} \mathrm{K}, 284 \mathrm{~K}, \mathrm{~kg} / \mathrm{m}^{3}$ and $\mathrm{g}=9.81 \mathrm{~m} / \mathrm{s}^{2}$ were used to determine the non-dimensional constant, $C_{T}=28$. The equation was found to be valid for $(z$ $\left.z_{0}\right) / Q_{c}{ }^{2 / 5}>0.20$. At $\left(z-z_{0}\right) / Q_{c}{ }^{2 / 5}<0.20$ the average excess temperature $(\Delta T$ ) was found to be equal to $836{ }^{\circ} \mathrm{C}$. The virtual source was found to obey the following relation (model and large-scale test):

$$
z_{0}=-3.73 w+0.083 Q^{2 / 5}
$$

Ingason [1] used the Froude scaling law to plot the velocity data. Fitting a curve (least squares) to the large-scale test for $Q_{c}{ }^{1 / 3} /\left(z-z_{0}\right)^{1 / 3}<3.4$ yielded the following equation:

$$
u=3.54\left[\frac{g}{c_{p} \rho_{\infty} T_{\infty}}\right\rceil^{1 / 3}\left(\frac{Q_{c}}{\left(z-z_{0}\right)}\right)^{0.45}
$$

Eqns. (3) and (5) are based on three model-scale tests (1:3) and one large-scale test, and Eqns. (4) and (6) are based on only one large-scale test. Ingason [1] pointed out that these correlations needed further validation in large scale, due to the limited large-scale data behind them. Additional large-scale tests with varying vertical flue spaces were therefore proposed. These additional tests are presented here and the experimental results were used to compare the data with Eqns. (3)-(6).

\section{EXPERIMENTAL SET-UP}

Four large-scale experiments were carried out under the Industry Calorimeter [7] in SP's Fire Hall. Both the convective and the chemical HRRs were measured. A Standard Class II commodity was 
used, consisting of double triwall corrugated paper cartons (each $12 \mathrm{~mm}$ thick). The double cartons were folded onto a sheet-metal liner and then placed directly onto the rack storage beams. No wood pallets were used. The outer dimensions of each carton were $0.8 \mathrm{~m} \mathrm{x} 1.2 \mathrm{~m} \times 1.0 \mathrm{~m}$, and the moisture content was $8 \%$ by weight. A double-row steel rack was used to hold the commodity. The widths of the vertical flues (w) were 75, 150, 225 and $300 \mathrm{~mm}$. The height of the horizontal flues was $300 \mathrm{~mm}$. The total height of the rack storage was $5.2 \mathrm{~m}$. The four standardised ignition sources were symmetrically placed, as close as possible to the centre flue space of the fuel array, at the bottom of each carton at the lowest tier. Centreline in-rack temperatures and velocities were measured at four elevations: $\mathrm{z}=0.97 \mathrm{~m}, 2.27 \mathrm{~m}, 3.57 \mathrm{~m}$ and $4.87 \mathrm{~m}$. Each of these positions corresponds to $2 / 3$ of the height of the carton. The ambient indoor temperature varied between 19 and $21^{\circ} \mathrm{C}$.
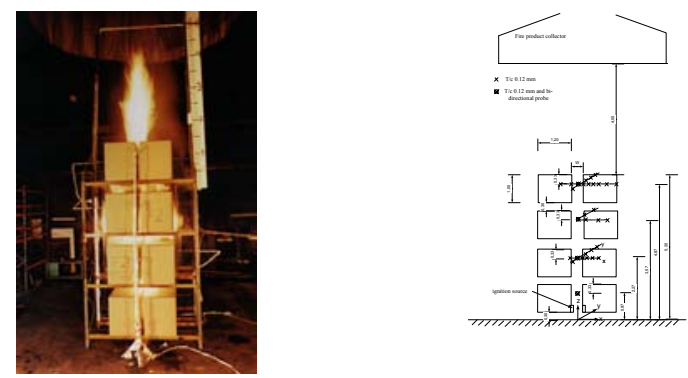

Fig. 2 - The experimental set-up and position of instrumentation (thermocouples and bidirectional pressure differential flow probes). Horizontal thermocouple assemblies were mounted in the $x$ and $y$ direction at $z=2.27 \mathrm{~m}, 3.57 \mathrm{~m}$ and $4.87 \mathrm{~m}$.

The in-rack temperatures were measured with welded type K (Chromel-Alumel) thermocouples, with a wire diameter of $0.12 \mathrm{~mm}$ (ten thermocouples were replaced by $0.25 \mathrm{~mm}$ welded type $\mathrm{K}$ thermocouples before the last test; $\mathrm{w}=225 \mathrm{~mm}$ ). The gas velocity was measured with bi-directional pressure differential flow probes $(D=16 \mathrm{~mm}$ and $\mathrm{L}=32 \mathrm{~mm})$ [12] at four different elevations. The thermocouples were attached to each bi-directional probe close to the sensor head. Fig. 2 shows the positions of the thermocouples and bi-directional probes. Horizontal thermocouple piles (supported on a steel rod) were mounted in the $\mathbf{x}$ and $\mathbf{y}$ axes at $\mathbf{z}=2.27 \mathrm{~m}, 3.57 \mathrm{~m}$ and $4.87 \mathrm{~m}$. Thermocouples at height $\mathrm{z}=2.27 \mathrm{~m}$ were positioned at $\mathrm{x}=-0.3,0,0.15,0.3,0.5$ and $0.7 \mathrm{~m}$ and at $\mathrm{y}=-$ $0.3,0,0.15,0.3,0.5$ and $0.7 \mathrm{~m}$. Thermocouples at height $\mathrm{z}=3.57 \mathrm{~m}$ were positioned at $\mathrm{x}=0,0.3$, $0.7 \mathrm{~m}$ and $1.2 \mathrm{~m}$ and at $\mathrm{y}=0,0.3$ and $0.7 \mathrm{~m}$. Thermocouples at height $\mathrm{z}=4.87 \mathrm{~m}$ were positioned at $\mathrm{x}=-0.7,-0.3,0,0.15,0.3,0.5,0.7,1.0$ and $1.3 \mathrm{~m}$ and $\mathrm{y}=-0.5,-0.3,0,0.15,0.3,0.5$ and $0.7 \mathrm{~m}$. No corrections due to radiation effects on the thermocouple measurements were carried out in this study due to the small diameter of the thermocouples; $0.12 \mathrm{~mm}$. The velocity was not corrected for variation in Reynold's number according to calibration curves reported in [12]. This was not deemed to be necessary due to the relatively high velocities measured. The data was recorded by a data logging system every other second. The flame height data was obtained from video recordings by comparing the 'average' fluctuation of the flame tip against a ruler painted on the boxes.

\section{DATA ANALYSIS AND RESULTS}

\section{Heat Release Rate}

Based on analysis of the HRR data presented in Fig. 1 and the new data obtained in this study (see Fig. 3), the initial fire spread in rack storage fires can be divided into three distinct periods of time: 
- $\quad$ The incipient period - 'incubation' period

- The fast upward fire spread period - 'take-off' period

- $\quad$ The horizontal fire spread period - 'eating-in' period

The incipient period can be named as the 'incubation' period, and is the time from ignition until the flames start to penetrate into the goods and the fire starts to propagate upwards. The incipient period can vary considerably in time and will depend on the size of the ignition source, the width of the flue space and finally the construction and type of the packaging material and the goods adjacent to the ignition source. If there are no goods just behind the packaging material (e.g. the wall of an empty box), the incipient time may be prolonged considerably. The fast upward fire spread period follows directly after the incipient period. It can be regarded as the 'take off' period of the upward fire spread. This period is usually shorter than the incubation period. Accompanying the fast upward flame spread, we have a slow lateral flame spread on the vertical surfaces within the flues. At the same time, we start to see flames penetrating into the horizontal flues (the horizontal gap between the stored boxes). The short horizontal flames will preheat the packaging material on the top and the bottom of the stored boxes. The length of the upward fire spread period will depend mainly on the thermal properties of the packaging material, the total height of the rack, the fire penetration rate at the ignition area and the width of the vertical flues. By the definition given here, the upward fire spread period ends when the vertical pyrolysis zone reaches the top of the rack storage. When the pyrolysis zone reaches to the top of the rack, we will observe continuation of the lateral flame spread inside the rack. This is the beginning of the horizontal fire spread period or 'eating-in' period. The fire starts to 'eat' its way into the goods (figuratively speaking) at the same time as it continue to spread horizontally on the vertical surfaces. At the same time, we start to observe lateral flame spread within the horizontal flues. The bottoms and tops of the boxes ignite, and shortly thereafter we see flames on the outer vertical surface of the boxes. Meanwhile, the fire in the vertical flues continues to penetrate into the commodity, and gradually spreads laterally all the way to the edge of the boxes. This period, the horizontal fire spread, is probably the most hazardous period. We can see it on the HRR curves in Fig. 1 as the fast rising part of the curve. This period is usually shorter than the incipient period, and longer than the upward fire spread period, see Table 1.

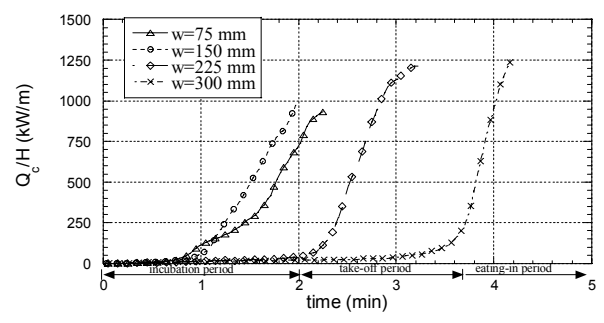

Fig. 3 - Convective HRR per height of the rack storage $(H=5.2$ m) measured by the Industry Calorimeter for four different flue widths (marks are data points). The different fire spread periods are indicated for $w=300 \mathrm{~mm}$. See Table 1 for more detailed information about the different fire spread periods.

Now we can explain the results of the measured heat release data for the different flue widths in regard to the three different phases of fire growth. By using this definition, we can also explain why we are able to normalise the convective HRR with the height, H. During the 'eating-in' period, the flame spread (on the vertical surfaces and within the horizontal flues), and thus generation of fuel, is probably similar in size at all tiers (two, three and four). Thus, if we normalise it to $\mathrm{H}$, we will get about the same results per tier or $\mathrm{H}$, as the 'take-off' period has very 
low values of convective HRR in comparison with the 'eating-in' period. A more general approach would be to use the exposed fuel surface area at each tier but for the purpose of this study we use $\mathrm{H}$ instead. An interesting observation from Fig. 1 is that the different groups become separated during the 'eating-in' period. Thus, the 'eating-in' period is highly dependent on the characteristic of the flame penetration into the commodity (generation of fuel vapours), and not so much on the thermal properties of the goods. The governing parameter of the fire growth during the 'eating-in' period is probably the flame radiance (sootiness, mean beam length etc) within the flues.

Table 1 The table show the time relation between the three different fire growth periods obtained for the different large-scale tests carried out.

\begin{tabular}{|c|c|c|c|}
\hline $\begin{array}{c}\text { Flue width } \\
\mathrm{w}(\mathrm{mm})\end{array}$ & $\begin{array}{c}\text { Approximate end of } \\
\text { 'incubation' time } \\
\text { (min:sec) }\end{array}$ & $\begin{array}{c}\text { Approximate start of the 'eating- } \\
\text { in' period (flame tip at top of } \\
\text { storage) } \\
\text { (min:sec) }\end{array}$ & $\begin{array}{c}\text { Approximate time } \\
\text { length of the 'take-off' } \\
\text { period } \\
\text { (sec) }\end{array}$ \\
\hline 75 & $0: 25$ & $0: 43$ & 18 \\
\hline 150 & $0: 32$ & $0: 58$ & 26 \\
\hline 225 & $1: 30$ & $2: 11$ & 41 \\
\hline 300 & $2: 35$ & $3: 37$ & 62 \\
\hline
\end{tabular}

The measured convective HRRs per height of the storage tested $(\mathrm{H}=5.2 \mathrm{~m})$ for the four different flue widths are presented in Fig. 3. Since we used the same ignition source for all the tests, it is apparent that the 'incubation' time is highly dependent on the flue width. This is also the case for the 'take-off' period. An indication of when the 'take-off' period is about to end, and the 'eating-in' period is about to start, is when the flame tip reaches the top of the storage. At this stage, the vertical pyrolysis zone is about $2 / 3$ of the flame height. Shortly after the flame tip reaches the top, the pyrolysis zone will reach the top (approx. a few seconds). If we assume that the 'incubation' time is the time from ignition to the time when the flames clearly start to move upwards (defined here as the time when the flame tip was $2 \mathrm{~m}$ from floor on video), we can estimate the 'incubation' time for the different tests in Fig. 3. The difference between the times the flames take to reach the top of the rack storage and the 'incubation' time is slightly less than the actual 'take-off' time (as defined here). The results are summarised in Table 1. Based on the results given in Table 1 and from Fig. 3, we can we can see that 'incubation' period ends just before the convective HRR curves per storage height $\left(Q_{d} / H\right)$ start to turn slightly upwards. Also the 'incubation' period and the 'takeoff' periods appear to be highly dependent on the vertical flue width. As can be seen in Fig. 3, the 'eating-in' period begins just before $Q_{c} / H$ starts the fast rise.

The slope of the curve during the 'eating-in' period apparently increases with the vertical flue width for $\mathrm{w} \geq 150 \mathrm{~mm}$. The behaviour is somewhat different for $\mathrm{w}=75 \mathrm{~mm}$, probably due to limited oxygen access into the flues, which slows down the fire growth rate. The reason for the increasing slope of the heat release curve with increased flue widths (w $\geq 150 \mathrm{~mm}$ ) is probably due to increased access to oxygen and increased mean beam length of the flames within the flues. This apparently influences the rate of the fire growth. Conclusively, the width of the vertical flue plays an important role in the initial fire growth rate of rack storage fires, especially the 'incubation' time and the 'take-off' time. The influence of the horizontal flues has not been considered in this study, but they may play an important role, especially in the later stage of the horizontal fire spread period (eating-in period). It should be pointed out that the basic form of Eqn. (2) was actually developed by Ingason [3] for the 'incubation' and the 'take-off' period. These periods include only the early part of the fire growth rate and not the most hazardous one; the 'eating-in' period. This was not fully understood by the author at the time Eqn. (2) was developed. The vertical flame spread according to the theoretical model in [3] is governed by an exponential term, and the lateral flame spread on the vertical surfaces is governed by a linear term. This contradicts the results 
obtained here, where the 'eating-in' period (no vertical flame spread) is dominated by the exponential term in Eqn. (2), and the 'incubation' and the 'take-off' period are governed by the linear term in Eqn. (2). Consequently, the physical model behind Eqn. (2) needs to be reconsidered due to the new results obtained in this study.

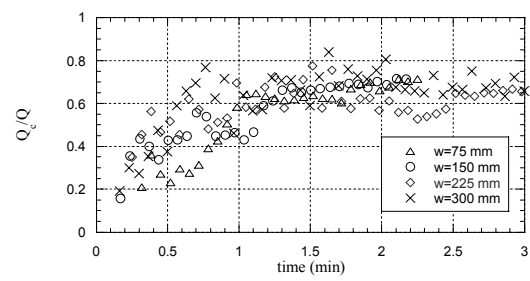

Fig. 4 - The ratio of convective $H R R$ $\left(Q_{c}\right)$ to the chemical HRR $(Q)$.

In the measurements of the HRR, we measured both the convective (Qc) and the chemical HRR (Q).

Usually the ratio $Q_{c} / Q$ is about 0.7 in open fires. It is of interest to investigate if this trend is similar for rack storage fires, and whether this ratio is dependent on the flue widths. The measured ratio of $\mathrm{Q}_{\mathrm{c}} / \mathrm{Q}$ is shown in Fig 4. It is apparent that, at the initial stage of the fire $(<1 \mathrm{~min})$, we have relatively high heat losses to the walls of the boxes. This appears to be higher for the narrower flues. Figure 4 shows that, after about one minute into the test, the ratio approaches a value of 0.65 -0.7 for all flue widths. For $\mathrm{w}=75$ and $150 \mathrm{~mm}$, this occurs in the 'eating-in' period of the fire growth, while for $\mathrm{w}=225$ and $300 \mathrm{~mm}$ it occurs in the 'incubation' period. This information may be of relevance to the results given for the temperature data in Figures 6 and 7. In the following, comparison is carried out between the results obtained in the present study and in an earlier study carried out by Ingason [1]. Parameters to be analysed are the in-rack flame height, in-rack gas temperature, in-rack gas velocity and horizontal temperature profiles within the rack storage.

\section{In-rack flame height}

The flame height data for the four new large-scale tests are plotted in Fig. 5 as well as the old large-scale test and the model-scale tests (1:3) from reference [1]. The majority of the data points belongs to the 'take-off' period. Eqn. (3) is plotted for comparison as well as the free-axisymmetric flame height using Heskestad's [8] flame height correlation assuming $w=D=0.15 \mathrm{~m}$. As can be seen, the agreement between Eqn. (3) and the experimental data is fairly good below $Q^{2 / 5} / w<60$. There appears to be a slight inconsistency between the new large-scale test with $\mathrm{w}=150 \mathrm{~mm}$ and the old test. We have stated earlier (see Fig. 1) that there were some differences in the development of the fire growth of these tests. This may partly explain the discrepancy in the results here, although one would expect the results to be independent of the growth rate. The slope of the experimental data presented in Fig. 5 tends to be considerably steeper than Eqn. (3) for $Q^{2 / 5} / w>65$. There is also some divergence for the widest flue width, $\mathrm{w}=300 \mathrm{~mm}$, for $Q^{2 / 5} / w>60$. The flame height for $\mathrm{w}=300 \mathrm{~mm}$ appears to correspond more to the flame height of a free axisymmetric fire plume (e.g. a pool fire). The divergence for smaller flues at $Q^{2 / 5} / w>60$ is probably due to limited access to entrained air as Q increases. Thus the flames tend to stretch upwards. There appears to be a lower and upper limit to the flue width for Eqn. (3). The results obtained here indicate that there is a need for a more rational correlation than Eqn. (3) fully to describe the flame height inside the rack storages tested. 


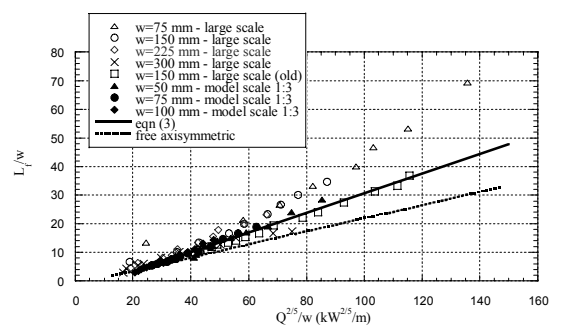

Fig. 5 - The dimensionless flame height $(L / w)$ plotted as a function of $Q^{2 / 5} / w$ for the large-scale tests. Equation (3) is based on earlier tests using model-scale tests and one large-scale test.

\section{In-rack excess centreline gas temperature}

The in-rack excess centreline temperature, $\Delta \mathrm{T}$, was plotted at elevations $\mathrm{z}=2.27 \mathrm{~m}, 3.57 \mathrm{~m}$ and $4.87 \mathrm{~m}$ : see Fig. 6 . The data used corresponds to tier numbers two, three and four. The plot in Fig. 7 shows that the temperature data follows the $-5 / 3$ power of the abscissa, in accordance with the axi-symmetric plume law for temperature, for $\left(\mathrm{z}-\mathrm{z}_{0}\right) / \mathrm{Q}_{\mathrm{c}}{ }^{2 / 5}>0.3 \mathrm{~m} / \mathrm{kW}^{2 / 5}$. Most of the data points following the $-5 / 3$ power of the abscissa

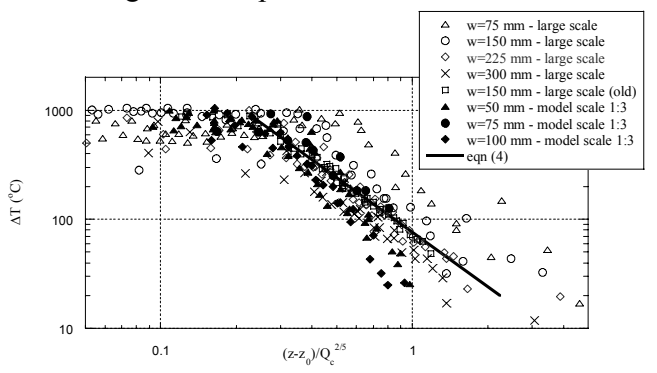

Fig. 6 - The excess centreline temperature versus $\left(z-z_{0}\right) / Q_{c}{ }^{2 / 5}$ for different flue widths, $w$. The temperatures were measured at tiers two, three and four. The solid line is Eqn. (4). Eqn. (5) was used to calculate $z_{0}$.

belong to the 'incubation' period, and some to the 'take-off' period. Most of the data points for (z$\left.\mathrm{Z}_{0}\right) / \mathrm{Q}_{\mathrm{c}}{ }^{2 / 5}<0.3 \mathrm{~m} / \mathrm{kW}^{2 / 5}$ belong to the 'eating-in' period, and some from the 'take-off' period. There is a tendency for smaller flue widths to yield higher excess temperatures than do wider flue spaces. Further analysis is needed to improve the correspondence between the experimental data and the influences of $\mathrm{w}$ for these large-scale tests. One way could be to improve the correlation of the virtual source, i.e. Eqn. (5). The data appears to follow the $-5 / 3$ power law reasonably well, but there is an offset from this trend which may be reduced by improving the correlation for the virtual source. It has also been pointed out that the convective HRR has been measured in the hood above the rack storage, whereas the convective HRR at each tier is dependent on the elevation (more convective heat is lost inside the rack at heights above the measuring points). This may also explain the scatter in the data presented in Fig. 6 . There is clearly a need to investigate this scatter more thoroughly. The temperature measured at $\mathrm{z}=0.97 \mathrm{~m}$, i.e. at the lowest tier, was relatively constant i.e. independent of the convective HRR and narrower flues tended to yield higher temperatures.

\section{In-rack centreline gas velocity}

The in-rack centreline gas velocity was plotted at elevations $\mathrm{z}=2.27 \mathrm{~m}, 3.57 \mathrm{~m}$ and $4.87 \mathrm{~m}$, and the results compared with Eqn. (6). In Fig. 7, the velocity is plotted for all four different flue widths. Eqn. (5) was used to calculate $z_{0}$. The scatter in the data is quite high, but there is a weak trend following Eqn. (6) for $Q_{c}^{1 / 3} /\left(z-z_{0}\right)^{1 / 3}<3 \mathrm{~kW}^{1 / 3} / \mathrm{m}^{1 / 3}$. There is a tendency that smaller flue widths yield higher centreline velocities than do wider flue spaces. 


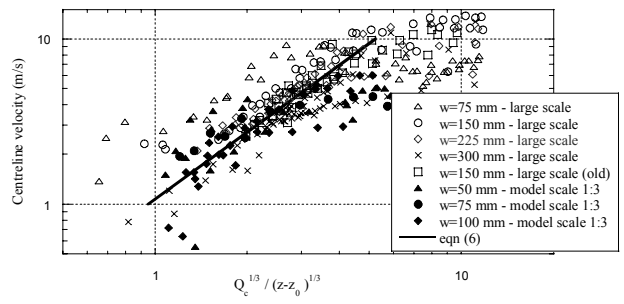

Fig. 7 - The in-rack centreline velocity as a function of $Q_{c}{ }^{1 / 3} /\left(z-z_{0}\right)^{1 / 3}$ for the four different flue widths, $w$, and tiers two to four. Data from reference [1] is also included.

The velocity measured at $\mathrm{z}=0.97 \mathrm{~m}$ was found to be independent of the convective HRR and was higher for narrower flue widths than for wider flue widths.

\section{In-rack thermal plume width}

The traditional way to define a thermal plume width, $\boldsymbol{b}_{\Delta \boldsymbol{T}}$, is the width to the point where the temperature rise has declined to $1 / 2 \Delta \boldsymbol{T}_{0}$. Here, $\mathrm{T}_{0}$ is the plume centreline temperature, and the width is measured from the flue centre-line. Measurements were carried out in the tests presented here in order to obtain a correlation for the in-rack thermal plume. Ingason and De Ris [9] presented a correlation for the thermal plume width, $\boldsymbol{b}_{\Delta \boldsymbol{T}}$, based on their experiments using four steel towers:

$$
\frac{b_{\Delta T}}{L_{f}^{1.1}}=0.177 \frac{z}{L_{f}}
$$

where $L_{f}$ is calculated from Eqn. (7) in reference [9]. Actually, Eqn. (3) in this paper can be used to calculate $\mathrm{L}_{\mathrm{f}}$ since the difference is relatively small. Figure 8 shows the in-rack excess gas temperature, $\Delta T$, normalised to the centreline temperature, $\Delta T_{0}$, and plotted as a function of $\mathrm{x} /\left(\mathrm{z}-\mathrm{z}_{0}\right) \mathrm{Q}^{0.12}$ for four different flue widths. This was a trial and error procedure, where we found the best correspondence for the data when using $\mathrm{x} /\left(\mathrm{z}-\mathrm{z}_{0}\right) \mathrm{Q}^{0.12}$. The variables used were originally derived from Eqn. (7) assuming that $b_{\Delta T}$ is associated with $\mathrm{x}, \mathrm{L}_{\mathrm{f}}$ is proportional to $\mathrm{Q}$ and $\mathrm{z}_{0}$ is associated with $\mathrm{z}$. The results became somewhat different than those obtained with Eqn. (7). If we assume a Gaussian type of distribution, we can use curve fit procedure to obtain the following equation for the experimental data (linear correlation coefficient, $\mathrm{R}=0.947$ ):

$$
\frac{\Delta T}{\Delta T_{0}}=0.996 e^{\left(-31 Q^{0.24}\left(\frac{x}{\left(z-z_{0}\right)}\right)^{2}\right)}
$$




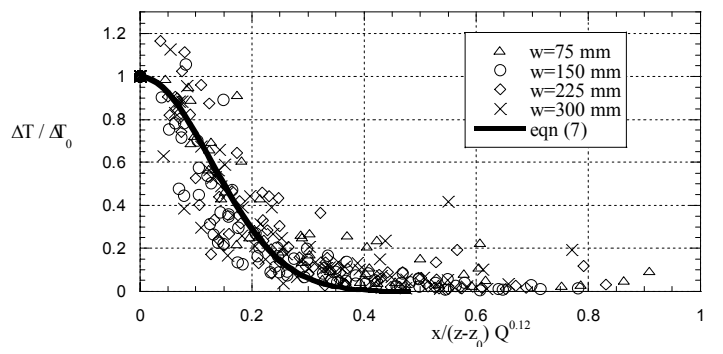

Fig. 8 - The in-rack excess

gas temperature profile measured at three different elevations.

The symmetry along the $\mathrm{x}-$ axis $(\mathrm{x}<0$ and $\mathrm{x} \geq 0)$ was found to be satisfactory (the maximum occurred at $\mathrm{x}=0$ in most cases), whereas the symmetry along the $\mathrm{y}$-axis was poorer (the maximum occurred at $\mathrm{y}=0.15 \mathrm{~m}$ in most cases). A plot of shifted data points by $0.15 \mathrm{~m}$ for $\mathrm{y} \geq 0$ was found to correspond well to the $\mathrm{x}$-axis data points.

\section{CONCLUDING REMARKS}

The aim of the study was to compare the results of four full-scale rack storage tests to the results of the 1:3 model-scale tests carried out in earlier studies [1]. The width of the flues between the stacked Standard Class II cartons was varied between $75-300 \mathrm{~mm}$, while the height of the horizontal flue was kept constant at $300 \mathrm{~mm}$. The in-rack flame height and the off-centreline gas temperature were plotted as a function of $\mathrm{Q}$ for different flue widths, and the excess centreline gas temperature and the centreline gas velocities were plotted as a function of $\mathrm{Q}_{\mathrm{c}}$ and $\mathrm{z}$.

The experimental study presented here shows that the vertical flue space is an important parameter for the initial fire growth rate in the rack. Three distinct periods of fire growth were identified: the 'incubation' period, the 'take-off' period and the 'eating-in' period. The last one was identified as the most hazardous period.

The overall agreement between the full-scale tests and the earlier model-scale tests was shown to be reasonably good. There is a great scatter in the large-scale data, which was also the case in the model case studies. Further analysis is needed to improve the correspondence between the temperature and velocity data and the influence of $w$ for these large-scale tests. One way could be to improve the correlation of the virtual source, i.e. Eqn. (5). The data appears to follow the axisymmetric power law correlations reasonably well, but there is an offset in the data, which may be reduced by improving the correlation for the virtual source. It has also been pointed out that the convective HRR has been measured in the hood above the rack storage, whereas the convective HRR at each tier is dependent on the elevation. This may also explain the scatter in the data presented here. Irrespective of this, there is a need to investigate this scatter more thoroughly.

\section{Acknowledgement}

Thanks to Dr John L. DeRis at Factory Mutual Research Corporation (FMRC) for his valuable contribution to the discussion of fire growth rates in rack storage fires. 


\section{REFERENCES}

1. Ingason, H., Plume flow in high rack storages, Fire Safety Journal 36 (2001) p. $437-457$.

2. Yu, H-Z. and Stavrianidis, P., The Transient Ceiling Flows of Growing Rack Storage Fires, Fire Safety Science-Proceedings of the Third International Symposium, pp. 281-290.

3. Ingason, H., Heat Release Rate of Rack Storage Fires, Proceedings of 9th Interflam 2001 Fire Science \& Engineering Conference, Edinburgh 17-19th September 2001, p. 731-740.

4. Person, H., Evaluation of the RDD-measuring Technique, RDD-tests of the CEA and FMRC standard plastic commodities, Swedish National Testing and Research Institute, SP-Report 1991:04

5. Persson, H., Commodity Classification - A more objective and applicable methodology, Swedish National Testing and Research Institute, SP Report 1993:70.

6. Arvidson, m., An Intermediate Scale Comparison between the FMRC and the EUR Standard Plastic Commodities, Brandforsk project 735-941, SP REPORT 1999:30, SP Fire Technology 1999.

7. Dahlberg, m., The SP Industry Calorimeter, For rate of heat release rate measurements up to $10 \mathrm{MW}$, SP Report 1992:43.

8. Heskestad, G., Engineering Relations for Fire Plumes, Fire Safety Journal, 7

(1984) 25-32.

9.

Ingason, H., and DeRis, J., Flame Heat Transfer in Storage Geometries, Fire Safety Journal 31 (1998) 39-60. 